\title{
The Military Health System: A Community of Solutions for Medical Education, Health Care Delivery, and Public Health
}

\author{
Robert P. Lennon, MD, JD, Aaron Saguil, MD, Dean A. Seebusen, MD, \\ Brian V. Reamy, MD, and Mark B. Stephens, MD, MS
}

Multiple strategies have been proposed to improve health care in the United States. These include the development of communities of solution (COSs), implementation of patient-centered medical homes (PCMHs), and lengthening family medicine residency training. There is scant literature on how to build and integrate these ideal models of care, and no literature about how to build a model of care integrating all 3 strategies is available. The Military Health System has adopted the PCMH model and will offer some 4-year family medicine residency positions starting in 2013. Lengthening residency training to 4 years represents an unprecedented opportunity to weave experiential COS instruction throughout a family physician's graduate medical education, providing future family physicians the skills needed to foster a $\operatorname{COS}$ in their future practice. This article describes our COS effort to synergize 3 aspects of modern military medicine: self-defined community populations, the transition to the PCMH model, and the initiation of the 4-year length of training pilot program in family medicine residency training. In this way we provide a starting point and general how-to guide that can be used to create a COS integrated with other current concepts in medicine. (J Am Board Fam Med 2013;26:264-270.)

Keywords: Community Medicine, Delivery of Health Care, Medical Education, Military Medicine, Public Health

\section{Communities of Solution: Why Now?}

Radical changes in the structure of American society during the early part of the 20th century led to the need to propose changes in health care delivery. The Folsom Report advocated for creating communities of solution (COSs) as one framework to integrate delivery of health care. ${ }^{1,2}$ COSs are partnerships designed to match seamlessly and efficiently local health needs with available health services. Early adoption of the COS concept, however,

This article was externally peer reviewed.

Submitted 25 July 2012; revised 6 November 2012; accepted 16 November 2012.

From the Naval Hospital Jacksonville Family Medicine Residency Program, Jacksonville, FL (RPL); the National Capital Consortium Family Medicine Residency, Fort Belvoir Community Hospital, Fort Belvoir, VA (AS, DAS); the Department of Family Medicine, F. Edward Hébert School of Medicine, Uniformed Services University, Bethesda, MD (BVR, MBS).

Funding: none.

Conflict of interest: none declared.

Corresponding author: Robert P Lennon, MD, JD, Naval Hospital Jacksonville Family Medicine Residency Program, Jacksonville, FL 32214 (E-mail: rlennon77@yahoo.com). was slow and incomplete. ${ }^{2,3}$ In the wake of World War II the U.S. health care system began to travel down a path of increasing fragmentation and subspecialization. As medical care has continued to expand exponentially in the latter half of the 20th century (without proportionate improvements in health outcomes), the original Folsom Report was revisited by policy makers to encourage once again COSs as a means to develop and sustain community-specific health programs. The vision outlined in the Folsom Report lacks a defined roadmap for how to create a COS. One of the few available models for developing a COS is from Vermont. ${ }^{4}$ It describes that state's prescribed method for developing state-funded COS. Although it is a valuable resource, it does not integrate other current medical concepts, and its specificity makes it difficult to generalize. This articles serves in part to act as a how-to guide for developing a COS using the vision outlined by the Folsom Report.

Two other current movements in primary care address the complexities of modern health care and 
Figure 1. Old-school isolation (stakeholders are fragmented).

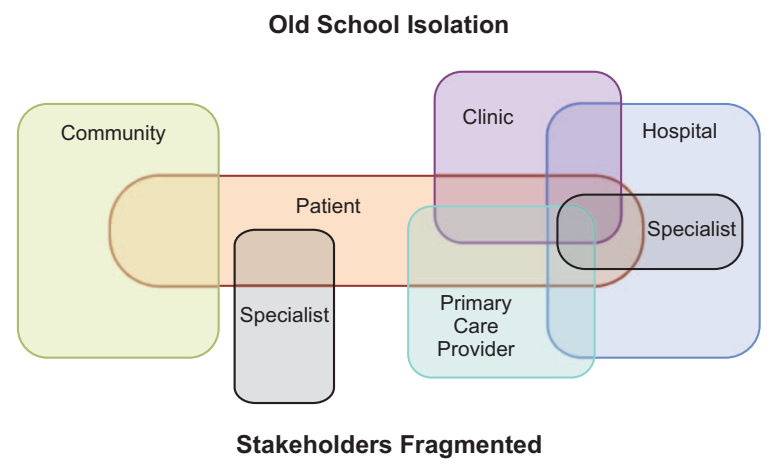

the improvement of patient outcomes. These are the patient-centered medical home $(\mathrm{PCMH})^{5}$ and the examination of different models for length of training during family medicine residency. ${ }^{6}$ The $\mathrm{PCMH}$ is a team-based model that coordinates all elements of medical care for patients, their families, and, potentially, communities. Early outcome-based data from practices implementing PCMH-based care suggest an improvement in preventive care, high patient satisfaction, and lower cost. ${ }^{7}$

Over the past decade, restrictions on work-duty hours have been implemented by the Accreditation Council for Graduate Medical Education to improve patient safety. A collateral impact of restricted duty hours is that physicians in residency training programs must contend with the need to integrate an increased fund of medical knowledge in a functionally reduced time frame. To address this, the Length of Training (LoT) Pilot Program, sponsored by the Accreditation Council for Graduate Medical Education, seeks to determine how to best provide the intellectual, procedural, and administrative skills new physicians need to lead PCMH practices upon graduation. In family medicine, it is anticipated that physicians trained in a 4-year residency will be better able to implement the PCMH in a COS framework to improve population health care outcomes. Specific areas of focus in the LoT pilot include building healthy living environments, increasing health literacy, and motivating patients and communities to "take ownership" of individual and community health needs. We describe the Military Health System (MHS) as one example of a COS. Our model specifically integrates PCMH and LoT concepts designed to improve health care and educational outcomes.

\section{What Makes a "Community"?}

The classic model of medical care (represented visually in Figure 1) has changed little since antiquity. Patients seek advice about and treatment for a perceived disease. This episodic model of acute care has created multiple problems in the current high-cost, procedurally-based environment of U.S. health care. To begin, most patients do not understand the cost of health care delivery. ${ }^{8}$ The complexities of billing, reimbursement, and insurance leaves most patients with limited moral hazard in terms of knowing exactly what any given test, procedure, or visit really costs. In addition, health care is often widely distributed across multiple medical entities, with poor communication between providers. This fragmentation often leaves patients and families in charge of coordinating care across increasingly complex systems. Furthermore, today's highly global and interconnected world makes it such that individual health decisions (such as choosing or declining vaccination, accepting or declining recommended preventive health services) can have disproportionate effects on population health and the societal cost of health care delivery. Finally, individuals frequently are unable to control many of the external determinants of health such as public safety, access to healthy foods, and walkable/ bikeable communities. Faced with these challenges, the need for a holistic, population-oriented COS comes into sharp focus.

The PCMH model provides a sound central platform around which to organize such a COS (Figure 2). We specifically define "local partnership" from a community-based perspective. As defined by Nutting, ${ }^{9}$ the term community can be un-

Figure 2. Community of solution with a foundation of the patient-centered medical home (stakeholders are merged).

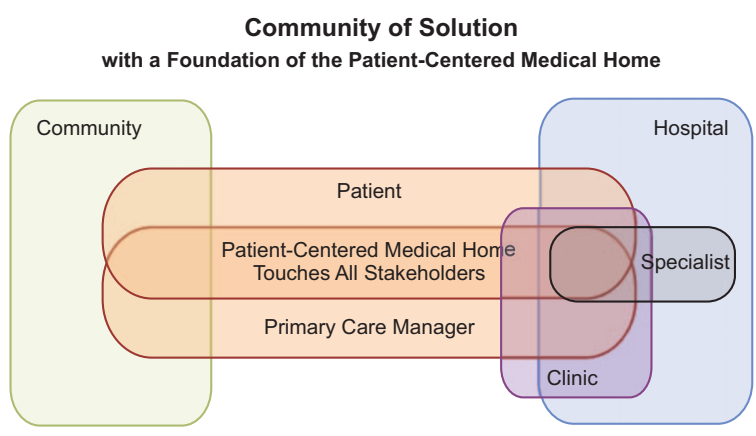

Stakeholders Merged 
derstood from 3 perspectives: (1) territories or space, (2) group memberships, and (3) sets of social structures and organization. Such an approach allows for a layered definition of community. When resource utilization is not limited by geographic proximity, global COSs such as the World Health Organization are necessary. When there are geographical or political breaks in societies, regional COSs such as the Western Africa Regional Health Network become important. Our MHS COS model specifically addresses local communities. This represents a local COS based on the PCMH physically located within hospitals on individual military bases and encompassing locally assigned patient populations.

The MHS has a strong motive to adopt the COS model. While bases are bound tightly by common devotion to the specific unit's military mission, the health care delivery system is often fragmented between on-base care and "in-town" civilian care, with no central organizing focus or center of communication. This has been exacerbated by more than a decade of high operational tempo, with frequent deployments of medical personnel. While the current MHS health care model includes support from public health officers, occupational health officers, physicians, nurses, and medical support staff, frequent manpower shortages exacerbated by deployments limit the workforce available to implement a COS. To ensure an adequate COS workforce we are, therefore, implementing this model at resident training sites. Residents are not able to be deployed, and by coordinating implementation with 4-year residency slots we can build dedicated COS support time into resident schedules. This residency-based COS model provides for organized community needs assessments and a centralized communication hub.

In and of itself, a local COS is a relatively simple concept. Considering the global interconnectedness of modern society, however, reality becomes more complex. This raises the question, What is the effective size limit of a local COS? The answer is best defined by the Swedish term lagom. While there is no direct English translation, lagom essentially means "just the right amount." The creation of a local COS is important in concept, but not only is it impossible to define the limits of a local COS applicable to all scenarios, it is not necessary. The local COS is an organic entity that will expand and contract in scope until it reaches the right size for the patient community it serves, as measured by the outcomes it chooses to achieve.

The organic nature of the COS within the MHS is exemplified by our approach to traumatic brain injury (TBI). ${ }^{10}$ Before the current wars in Iraq and Afghanistan, the military medical TBI research and practitioner community was similar to that of the civilian world, dominated by neurologists, psychiatrists, and emergency department physicians. As TBI has become the dominant mechanism of injury to our deployed troops, that COS has expanded to include a TBI research center in theater, active participation in TBI research and treatment within all primary care specialties, and regular TBI briefings to all medical personnel. The TBI COS has organically reshaped itself to meet situational needs.

Our approach is to define clearly the boundary parameters of an effective COS, provide a model for execution of the COS, and educate new primary care providers about how to create and maintain a COS by having them actively participate in the creation and management of a COS throughout their training.

\section{Communities of Solutions and Military Health Care: A Generalizable Model}

The populations for which we are developing COSs are those served by the 5 family medicine residency programs sponsored by the U.S. Navy. These programs are located at Naval Hospital Jacksonville, FL; Naval Hospital Pensacola, FL; Camp Pendleton, CA; Camp LeJeune, NC; and Naval Hospital Bremerton, WA. Each site cares for active-duty members, their families, and eligible military retirees. Health care providers structured in PCMH teams are responsible for managing health care from preconception counseling through endof-life care. All 5 sites share significant structural and philosophical similarities, which allow us to build an overarching COS framework that can be applied generically across sites.

In many ways the participating military bases mirror civilian metropolitan areas. Each base has embedded infrastructures to support work, housing, and recreation. Specific agencies dedicated to health, public works, housing, and resource management exist locally to keep the base in a fully operational status. Each base, therefore, represents a self-contained "city" in many ways. Military bases also have a defined command structure that is sim- 
ilar to city or county governments. Base leadership interacts with local civilian community leaders the same way that government leaders from any other pair of metropolitan areas in close geographic proximity would. Since many military families also live in areas surrounding the base, by necessity an inclusive COS includes these civilian partners.

\section{Creating Local Communities of Solution: The MHS-PCMH Model}

As part of the LoT pilot program we are creating 4-year family medicine residency tracks at 5 U.S. naval hospital family medicine residencies. Each program includes a longitudinal curriculum covering cognitive and procedural skill sets that will allow family physician graduates to coordinate, implement, and lead a PCMH-centered COS within the MHS. Each site has a specific curriculum that leverages local strengths and focuses on physician leadership and the full scope of practice. To create COSs that best meet local needs, we will be using the strategy outlined in Figure 3, an adaptation of the Plan, Do, Check, Act cycle.

\section{Step 1: Identify Key Stakeholders}

When developing a local COS it is important to recognize that PCMH physician leaders cannot always predict which of the stakeholders will choose to be involved. This necessitates an open solicitation for stakeholders. An expanded list of likely COS stakeholders is provided in Table 1. We empirically presume that common and indispensible stakeholders are the patient, their resident PCMH physician-leader, and the faculty mentor. Depending on local goals and needs, additional early stake-

Figure 3. Community of solution methods.

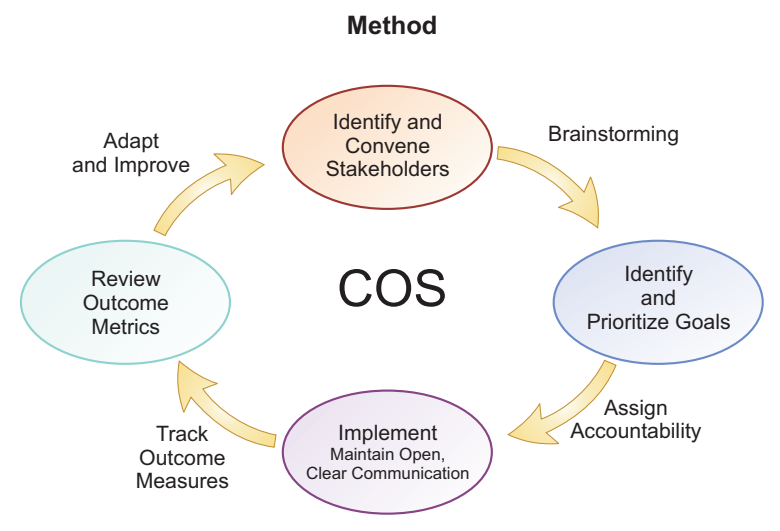

Table 1. List of Likely Communities of Solution (COS) Stakeholders

- Patients

- Primary care physicians

- Families

- Base commanders

- Public health officers

- Insurers

- Neighborhoods*

- Businesses/business associations (on and off base)

- Schools (on and off base)

- Policy makers (base command, similar to a city government)

- Regulatory bodies

- Service providers ${ }^{\dagger}$

- Food providers ${ }^{\ddagger}$

- Branch clinics

- Unit physicians ${ }^{\S}$

- Managers of recreational spaces ${ }^{\text {II }}$

${ }^{*}$ Most base housing is a mix of apartment and single-family housing.

${ }^{\dagger}$ Emergency medical services, police, fire, water, sanitation (a mix of on- and off-base providers).

${ }^{\ddagger}$ Restaurants, grocery stores, convenience stores on base.

${ }^{\S}$ Many military units have a dedicated physician to provide their primary care.

${ }^{\mathbb{I}}$ Military bases offer an array of recreation, from golf courses to marinas.

holders within the hospital and base community can be identified to help shape objectives and desired health outcomes.

\section{Step 2: Convene the Stakebolders}

Once stakeholder groups are identified, key representatives will be invited to participate in a series of focus groups designed to shape goals and objectives for the local COS. This invitation is not exclusive because there are likely additional stakeholders that have not yet been identified. During initial meetings, representatives from each stakeholder group will describe their role in the health of the population, the outcome measures they would like to track, challenges they currently face, and what health-related outcomes they believe would improve with collaborative help.

\section{Step 3: Identify and Prioritize the Goals of the COS}

After initial stakeholder meetings, the next step is to prioritize action items for each local COS to address. We anticipate that each site will begin with 1 or 2 of the most pressing local community health issues and expand as needed over time. Starting 
with small projects will facilitate early success and allow the newly formed COS to build momentum for larger and longer-term projects.

Three baseline goals of any MHS COS would be (1) improve public safety in homes, neighborhoods, schools, and places of work and recreation; (2) improve preventive health by maintaining a COS that integrates public health services into work, school, and recreational areas; and (3) track commonly agreed upon public health metrics to promote better community health and public safety (eg, safe water, safe buildings, safe neighborhoods). Other goals will be identified locally. Table 2 represents an example of goals generated using a brainstorming model. Prioritizing individual COS goals will take time and collaboration to develop trust and ensure that selected goals are achievable, have measurable outcomes, and do not represent a threat to other stakeholders. We will prioritize reported data when available and rely on the COS members' intuitive sense of high versus low values (seen in much of the early literature on cost-effectiveness evaluation) to create a low-resolution, doable action list for interventions that do not have data readily available.

\section{Step 4: Identify the Stakebolder Accountable for Each Action Item, the Method of Tracking Cost and Outcome, and the Timeline for Implementation}

The following narrative serves as a "before" example of how a military community medical problem was addressed and allows us to highlight the importance of clearly identifying stakeholders and tracking costs and timelines.

A military primary care clinic had an influx of young adults presenting with symptoms of allergic rhinitis during a month when pollen levels were high. Some, but not all, had a history of seasonal allergies. This rise in allergic rhinitis initially was attributed to the season, but it soon emerged that

\section{Table 2. Brainstormed Goals Created During}

\section{Communities of Solution (COS) Meetings}

- Have flu vaccines available at major command events

- Widen all base roads to include bike lanes

- Fix existing sidewalks to promote walking

- Increase police presence in off-base neighborhoods with high crime

- Tax unhealthy foods at point of purchase

- Require providers to provide care in patient homes all these patients lived in the same building, and many of their families were affected by similar symptoms. This was not initially obvious because the clinic was seeing primarily spouses while the active-duty service members had gone to their unit physicians and their school-aged children went to their school nurses. The unit and school providers also had noticed an increase in allergic rhinitis, but there was no system in place for collaborative communication or sharing data.

Eventually an investigation by a public health officer revealed that 1 month earlier a water main broke in the apartment building the patients shared. The damage was minimal, but the basement walls had become overgrown with mold. The basement areas were for storage and not considered to impact the living spaces and therefore were given a low priority on the housing authorities' agenda. As each involved party began to communicate-an impromptu COS - the problem was reprioritized, the mold was removed, and the patients' symptoms resolved.

If a COS had been in place at the time of the water main break, the public health officer might have been able to identify the potential health hazard immediately. This would have allowed for an immediate tasking by the base commander to the housing authority to address what seemed to them to be a relatively innocuous water leak. Because the cost of fixing the leak would have been identical regardless of when it was fixed, any savings realized by fixing the leak sooner rather than later would be of value. While the public health officer might not have been able to quantify an exact cost of delay (it would be difficult to predict the extent of mold growth and the effect of lost work time), the potential for significant increased costs of delay would likely prompt immediate action. In this case the timeline could be based on a risk-benefit analysis of other housing authority projects. Table 3 lists possible outcome metrics that could be tailored for each intervention.

\section{Step 5: Review Outcome Metrics}

As goals are being implemented, progress will be shared through an interactive COS portal (website). This portal allows stakeholders to comment and act as a social network to strengthen ties within the COS. This portal also allows for the identification of previously unrecognized stakeholders and adapts action items based on real-time feedback. Regularly 
updated data allows all invested parties to evaluate each goal or action item from their own perspective. Local media portals (school bulletins, neighborhood listservs) will describe projects and results in terms that are readily understandable to the lay public. The goal is to improve the education, health, and safety of the ultimate stakeholder: the patient.

One benefit to implementation within the military setting is access to universal communication networks between all stakeholders. At the base commander's order, information can be disseminated to all potential stakeholders within the military system through direct mail to beneficiaries, written and verbal contact through the chain of command to all military personnel, bulletins distributed at all base facilities (from grocery stores and gas stations to schools), and radio and television advertisement through the Armed Forces Network (often the only or primary source of mass media for personnel stationed overseas). Users of the MHS are solicited for feedback actively through direct mail surveys and paper feedback forms after every visit and passively through electronic kiosks at most MHS point of care sites that offer users the option of providing anonymous or personal feedback. This level of communication is admittedly not as readily available in civilian communities, but it might be approximated by expanding current Public Health Service educational announcements through mass media and Internet initiatives.

Interventions with immediate, measurable, and positive results might be expanded. Interventions with detrimental results (in terms of either patient outcomes or costs) might be eliminated. Intermediate items can be modified based on the data. The longer outcome metrics (Table 3) are tracked, the greater the ability to identify significant relationships and make meaningful process improvements.

\section{Step 6: Repeat the Cycle}

Each COS is organic and by nature will change its composition, scope, and action items over time. By creating a circular model, we are inviting participants to join at any stage of the process. This may include simple changes in personnel, broader changes in scope, or the separation of a COS that has become unwieldy into $\geq 2$ COSs that can be effective in their respective areas of focus. To integrate further the PCMH and the LoT pilot program, residents selected for 4-year residency training
Table 3. Outcome Metrics to be Tracked for Process Improvements

- HEDIS

- ORYX

- Percentages of immunization

- Costs

- Change in lost work days

- Morbidity and mortality (all cause or specific cause)

- Inpatient admissions

- Emergency department visits

- Arrests

- Convictions

- Teenage pregnancy

- Alcohol use

- Drug use

- Citizen satisfaction

- PCM satisfaction

- Community, PCP, specialist revenue

HEDIS, Healthcare Effectiveness Data and Information Set; PCM, primary care manager; PCP, primary care physician.

will have longitudinal time dedicated to leadership and research built into their schedules. This helps to provide each site with a renewable stream of researchers to support tracking COS evolution and outcome data and provides the community at large a stream of LoT residents trained and experienced in developing COS.

\section{Limitations}

We see 3 primary barriers to generalizing the MHS COS model. First and foremost, the military command structure allows for implementation by singular direction. The scope of this authority extends to all stakeholders. There is no parallel in the civilian world. Government authorities have this ability within their own structure, but their order cannot compel participation by other stakeholders. However, because COS systems are designed to improve patient care, and all health care dollars ultimately flow from the patient (directly or indirectly through the political process), economic forces will likely shape analogous COS in civilian communities. Second, stakeholder communication is much easier in the MHS. Finally, civilian systems are more restricted by direct costs than is the military system. Within the MHS, collateral duties such as COS development and participation can be assigned without extra compensation to stakeholders. Optimizing COS in civilian communities will likely require a change in compensation structures. We believe, however, that if the value of COSs 
within the MHS can be demonstrated, civilian communities will demand increased value within their communities and that the MHS COS model will serve as a template for success for civilian health care systems.

\section{Conclusion}

COSs have the potential to radically improve population health outcomes. By integrating a new 4-year family medicine residency LoT pilot program with the implementation of a PCMH in the MHS, our model represents a unique COS that spans medical education, health care delivery, and public health.

The authors thank Ms. Linda G. Culp, Visual Information Specialist, Uniformed Services University Media Services, Rockville, MD, for her excellent images.

\section{References}

1. The Folsom Group. Communities of solution: the Folsom Report revisited. Ann Fam Med 2012;10:250-60.

2. NCCHS. Health is a community affair-report of the National Commission on Community Health Services (NCCHS). Cambridge: Harvard University Press; 1967.

3. The American Board of Family Medicine Young Leaders Advisory Group. Improving America's health requires community-level solutions: Folosom revisited. Am Fam Physician 2012;86:1-2.
4. Department of Vermont Health Access. Vermont blueprint for health implementation manual. Available from http://hcr.vermont.gov/sites/hcr/files/ printforhealthimplementationmanual2010-11-17.pdf. Accessed July 24, 2012.

5. National Committee for Quality Assurance. Patientcentered medical home. Available from http://www. ncqa.org/tabid/631/default.aspx. Accessed May 23, 2012.

6. Accreditation Council for Graduate Medical Education. Call for proposals, family medicine length of training pilot. Available from http://www.aafp.org/ online/en/home/publications/news/news-now/ education-professional-development/20120427 acgmepilot.htm. Accessed May 23, 2012.

7. Grumbach K, Grundy P. Outcomes of implementing patient centered medical home intervention: a review of the evidence from prospective evaluation studies in the United States. Updated November 16, 2010. Available from http://www.pcpcc.net/files/ evidence_outcomes_in_pcmh.pdf. Accessed July 16, 2012.

8. Gaynor M, Polachek S, National Bureau of Economic Research. Measuring ignorance in the market: a new method with an application to physician services. NBER working paper no. 3430. Available from http://www.nber.org/papers/w3430. Accessed March 13, 2013.

9. Nutting PA. Community-oriented primary care: from principal to practice. Albuquerque: University of New Mexico Press; 1987.

10. Cifu DX, Cohen SI, Lew HL, Jaffee M, Sigford B. The history and evolution of traumatic brain injury rehabilitation in military service members and veterans. Am J Phys Med Rehabil 2010;89:688-94. 